\title{
LA HOMOSEXUALIDAD EN PRECEPTOS DE LA RELIGIOSIDAD CRISTIANA
}

\author{
HOMOSEXULITY IN PRECEPTS OF CHRISTIAN RELIGIOLITY
}

Douglas Verbicaro Soares

Universidade Federal de Roraima, Boa Vista, RR, Brasil. E-mail: douglas_verbicaro@yahoo.com.br

DOI: http://dx.doi.org/10.31512/missioneira.v23i1.334 Recebido em: 29/03/2021 Aceito em: 02/07/2021

\begin{abstract}
Resumen: El estudio tiene como objetivo hablar sobre la orientación homosexual y su relación con la ideología cristiana, en especial la católica, como fuente de inspiración para la sociedad brasileña en cuestiones de inclusión de las personas homosexuales y, también en el combate a la discriminación en el país. Para eso ha sido realizada una investigación basada en fuentes bibliográficas que retrataron la condena de la homosexualidad desde algunos de los preceptos bíblicos. Para la investigación ha sido empleada una metodología basada en la fuente bibliográfica multidisciplinar, con relación con el derecho, la historia, etcétera... Como indagaciones el estudio buscó algunas respuestas: ¿Cómo ha sido tratada la homosexualidad por la ideología cristiana? ¿El Papa Francisco ya ha se manifestado sobre esa orientación sexual? La investigación concluye por la existencia de obstáculos que discriminan a las personas homosexual en el ámbito de la Iglesia Católica.
\end{abstract}

Palabras-claves: Condena. Homosexual. Igualdad.

\begin{abstract}
The study aims to talk about homosexual orientation and its relationship with Christian ideology, especially Catholic ideology, as a source of inspiration for Brazilian society in matters of inclusion of homosexual people and also in the fight against discrimination in the country. For this reason, research has been carried out based on some bibliographic sources that portrayed the condemnation of homosexuality since the biblical precepts. For research has been used a methodology based on the multidisciplinary bibliographic source, in relation to law, history, etc....As research the study sought some answers: How has homosexuality been treated by Christian ideology? Has Pope Francis already expressed himself on this sexual orientation? The research concludes because of the existence of obstacles that discriminate against homosexual people within the Catholic Church.
\end{abstract}

Keywords: Condemnation. Homosexual. Equality.

\section{Introducción}

lestudio tiene como objetivo desarrollar la discusión social sobre la homosexualidad y
los obstáculos que impiden que esas personas puedan ser tratadas sin discriminación en Brasil, en especial en el ámbito de la Iglesia Católica. Así, la presente investigación buscó visibilizar la experiencia histórica del Cristianismo, que pasó de la condenación de la homosexualidad, en 
el surgimiento de la ideología católica, hasta la visión del Papa Francisco sobre esa orientación sexual.

Para el trabajo ha sido empleada una metodología basada en fuente bibliográfica multidisciplinar, con relación al derecho, la historia, la psicología, etcétera... El estudio tiene dos (2) apartados, más la introducción, consideraciones finales y referencias. El primero versa sobre la Iglesia Católica Apostólica Romana y la homosexualidad. El segundo retrata el posicionamiento del Papa Francisco sobre esa orientación sexual.

De ese modo han sido realizadas algunas preguntas para el estudio: ¿Cómo ha sido tratada la homosexualidad por la ideología cristiana? ¿El Papa Francisco ya ha se manifestado sobre esa orientación sexual? Estas indagaciones han sido las preguntas para el trabajo, que tuvo como principal objetivo el desarrollo de la discusión social sobre la homosexualidad en el país.

\section{La Iglesia Católica Apostólica Romana y la homosexualidad}

Con los relatos de San Agustín ocurre un cierre de mentalidad cuanto la sexualidad humana, donde se consolida el ideario de que las prácticas sexuales tendrían que ver solamente con la esencia natural de la procreación humana y mantenimiento de la especie, ${ }^{1}$ olvidando así el carácter del placer, del descubrir de la sexualidad (entre ellas: el sexo anal, la masturbación, las prácticas orales y otras). De este modo, condenando las conductas que supuestamente vulneraban a la primera, es decir, excluidas las distintas formas de expresión de la sexualidad humana, siendo la homosexualidad una de ellas para la influencia de la religión cristiana y las sociedades que, también, usan de sus bases como referencia moral, ideológica de las conductas a ser seguidas por sus integrantes.

Para el Santo de la Iglesia Católica, las prácticas homosexuales eran vistas como conductas extravagantes y raras, según él: todo el coito que se realiza con un objeto diferente a la procreación era completamente pecaminoso. ${ }^{2}$ Del mismo modo, Ayensa nos recuerda que:

Gran parte de esta nueva actitud negativa hacia la homosexualidad se debe a los escritos e influencias de Tomás de Aquino ${ }^{3}$, quien en su Suma Teológica (12661273) determina que la sodomía homosexual, junto al bestialismo y el sexo oral y anal en general, constituyen formas de sexo antinaturales que son pecados sólo secundarios en gravedad al asesinato.

Lo curioso que con el movimiento reformista denominado: La Doctrina de Fe de la Iglesia Católica, a partir de la encíclica Rerum Novatum, editada en 1891, por el Papa de la época, León XIII, ese retorno a las ideas de Tomás de Aquino, convertido en Santo por la Iglesia, esa institución basándose en las ideas de Aquino sobre el bien común, y la concepción tomada de la existencia de una vida humana digna. Ese ideario servirá de base para la valoración de la dignidad al trabajo y de lo trabajador. Con los cambios sugeridos por la ideología de la Iglesia Católica, como bien aclara Ferreira Filho: se llega asi en la afirmación de derechos que exprimen las necesidades minimas de una vida consensuada con la dignidad del ser humano, creado a imagen y

1 FELGT. La iglesia Católica y la homosexualidad. Disponible en: <http://www.felgt.org/files/docs/d9474064b9f6.pdf>. Acesso en: 26 feb. 2021.

2 IZQUIERDO, Alejandro. Evolución del Derecho de Igualdad de Lesbianas y Gays. Trabajo de Grado. Universidad de Salamanca: Programa de Doctorado Pasado y presente de los derechos humanos, Salamanca, España, 2006, p. 52.

3 BRAVO, Isidre. La Mirada de Zeus. Antología sobre la fascinación masculina por los muchachos en la literatura griega y latina.

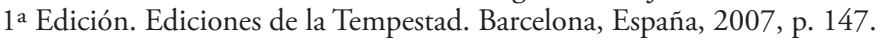


similitud de Dios. De ahi el derecho al trabajo, a subsistencia, la educación e etc. ${ }^{4}$

En la misma línea de racionalidad, otros pensadores opinan que: en la sociedad occidental, judeocristiana, la homosexualidad ha sido considerada como un delito punible por la Ley. El caso del irlandés Oscar Wilde, se ha tornado uno de los más notorios en los últimos siglos. ${ }^{5}$

A lo largo de la historia humana, la homosexualidad ha sido castigada con cárcel (hasta cadena perpetua), con multas, torturas, castración e incluso con la quema en la hoguera. Por más difícil que se le tenga sido asumir y vivir esa orientación del deseo homosexual sexual en los tiempos, muchas personas de relevante destaque social acabaran revelando esa condición, entre ellos reyes, miembros aristocráticos, intelectuales, científicos, poetas, cantores. ${ }^{6}$

De acuerdo con el posicionamiento de la cúpula de la Iglesia Católica, se sigue manifestando que la homosexualidad es un problema global y urgente, que no sólo estaría produciendo la desconstrucción de la persona y de la civilización, sino que es necesario tratar como una terapia integral. ${ }^{7}$ Según esa idea, el editorial Biblioteca de Autores Cristianos ha traducido las actas de un simposio que ocurrió en Roma, en el año de 2008, con la participación de la jerarquía de la iglesia, que ha sido materializado a través de la obra publicada: amar en la diferencia, que tiene por objetivo enfocar la homosexualidad como una patología a ser erradicada en la sociedad.

Con base en los argumentos de la Iglesia Católica, llevando en consideración a las enseñanzas espirituales de las palabras de Dios, ha manifestado que el acto homosexual, es decir: las relaciones entre personas del mismo sexo con características sexuales serian el acometimiento de un pecado grave por las personas que lo realizan. ${ }^{8}$ Hecho este defendido por la Congregación para la Doctrina de la Fe, donde se declaró en el año de 1975: Según el orden moral objetivo, las relaciones homosexuales son actos privados de su regla esencial e indispensable. En las Sagradas Escrituras están condenados como graves depravaciones e incluso presentados como la triste consecuencia de una repulsa de Dios. ${ }^{9}$

Para las fuentes bíblicas, las conductas homosexuales tiene reprobación, como por ejemplo en el Génesis, pasando por Levítico, o hasta incluso en las Cartas escritas por San Pablo ${ }^{10}$ (pasiones deshonrosas, extravíos - Rom. 1,26-27 y también en Corintios 6,9 y Timoteo 1,10). Puede ser citado en el texto de San Pablo a los romanos: Los romanos cambiaran la verdad de Dios por la mentira, adoraran y servirán a criaturas desplazando al Creador, que es bendito eternamente. Por eso, Dios os estregó a pasiones degradantes: a sus mujeres cambiaran las relaciones naturales por relaciones contra la naturaleza, los hombres, igualmente, abandonaran las relaciones naturales

4 FERREIRA FILHO, Manoel. Direitos humanos fundamentais. Editora Saraiva. 4a Edição. São Paulo, Brasil, 2000, p. 45.

5 AYENSA, José Ignacio. Estudiando La Homosexualidad. Teoría e investigación. 1a Edición, Ediciones Pirámide. Madrid, España, Ediciones Pirámide, 2008, p. 130-1.

6 AYENSA, José Ignacio. Estudiando..., op. cit., p. 131.

7 LAMAREA. Llega a España el Manual del Vaticano contra la homosexualidad. Disponible en: <http://www.lamarea. com/2013/06/11/la-iglesia-publica-en-castellano-un-manual-para-tratar-la-homosexualidad/>. Acceso en: 26 feb. 2021.

8 BRAVO. Isidre. La Mirada de Zeus..., op. cit., p. 108-9.

9 ACIPRENSA. La enseñanza de la Iglesia Católica sobre la homosexualidad. Disponible en: <http://www.aciprensa.com/ Familia/homosex-catolicis.htm>. Disponible en: 26 feb. 2021.

10 Cor. 6, 9-10: ni los impuros, ni los idólatras, ni los adúlteros, ni los afeminados (malakoí), ni los homosexuales (arsenokoítai)... heredarán el Reino de Dios;Tim. 1, 9-11: teniendo bien presente que la ley no ha sido instituida para el justo, sino para los prevaricadores y rebeldes, para los impíos y pecadores,..., adúlteros, homosexuales (arsenokoítai), traficantes de seres humanos; Rom. 1, 26-27: por eso los entregó Dios a pasiones infames; pues sus mujeres invirtieron las relaciones naturales por otras contra la naturaleza; igualmente los hombres, abandonando el uso natural de la mujer, se abrasaron en deseos los unos por los otros, cometiendo la infamia de hombre con hombre, recibiendo en sí mismos el pago merecido de su extravío. Cuanto la referencia a la homosexualidad entre mujeres en la Biblia: sus mujeres invirtieron sus relaciones naturales por otras contra la naturaleza. IZQUIERDO, Alejandro. Evolución del Derecho...op. cit., p. 50. 
con la mujer, inflamaran se en deseos unos por los otros, cometiendo la infamia de hombre con hombre y recibiendo el justo saldo de su des-reglamento.

De acuerdo con el capítulo bíblico del apocalipsis de Pedro, se explicita que otros hombres eran arrojados desde una gran roca y caían al fondo; más tarde, sus custodios los obligaban a subir de nuevo [...] y asi su tormento no terminaba nunca; (eran) los que mancharon su cuerpo comportándose como mujeres. ${ }^{11}$ Así como el contenido previsto en las Antiguas Actas del Concilio Eliberritano de Granada, que informaba la condena de la pederastia por parte de la Institución Cristiana: a los que cometen estupro con los muchachos ni siquiera en las puestas de la muerte se les suministrará la comunión. ${ }^{12}$

No se puede olvidar que en la época de la Inquisición de la Iglesia Católica, la condena a la homosexualidad ha estado presente de modo fervoroso, materializado a través de castigos físicos a las personas que cometiesen esa práctica en sociedad, incluso con la pena capital por este supuesto crimen pecaminoso.

Algunos de estos casos pueden ser visibilizados en los relatos de Pedro de León, visitador de la cárcel de Sevilla - Jerez de la Frontera, en el año de 1545/ Sevilla, en el año de 1632. De acuerdo con el Compendio 1592 y el Libro de Ajusticiados de 1615, muchos han sido los casos en que la inquisición condenó a personas a muerte por realizaren conductas homosexuales. ${ }^{13}$ Para ejemplificar algunos: a) El caso del aguacil - donde un cierto Quesada, era detentor de una casa de juegos y recibía en este sitio jóvenes, y realizaba tocamientos con el intuido de practicar conductas pecaminosas con los mismos. Condenación a la muerte en la hoguera; b) El caso de Francisco Galindo, que usaba determinadas ropas consideradas llamativas para ser usadas por un hombre, lo que le hacía parecer más una mujer, había denunciado a otros hombres de la sociedad, incluso a miembros de la propia Iglesia en las conductas consideradas nocivas y pecaminosas, entre estos denunciados, estaba el Fray Pascual Jaime, que ha sido quemado junto a su cómplice. Misma suerte ha tenido D. Alonso Celles Gixón, primero condenado al garrote para que a posteriori a la hoguera. Así como Francisco de Zarate y Mateo de Salvatierra, que han sido condenados a muerte por tocamientos deshonestos entre ellos.

Según otras previsiones en la Biblia: Si un hombre cohabitar sexualmente con un varón, cometerán ambos un acto abominable, serán los dos punidos con la muerte y su sangre caerá sobre ellos - Levítico 20, 13-14; No te acostarás con varón como con mujer; es abominación. Levítico 18, 22. ${ }^{14}$ Además de los textos citados, también se pueden evidenciar los que tienen que ver con el pecado de Sodoma: Gn 19, 1-29. Al analizarlo tendremos que hacer el paralelo con Jue 19, 22-30. Estos textos son referencia a la historia del pecado y de la alienación creciente del hombre. Así como los que mencionan los "prostitutos sagrados": Dt 23, 17; 1R 14, 24; 15, 12; 22,$46 ;$ Job 36, 14. Se trata de textos que condenan en primer lugar la sacralización pagana de la prostitución varonil, ocupándose, pues, de la homosexualidad ejercida en los lugares sagrados durante los cultos orgiásticos. ${ }^{15}$

Estos pasajes del Viejo Testamento, que tienen relación con las citaciones a la

11 BRAVO, Isidre. La Mirada..., op. cit., p. 184.

12 BRAVO, Isidre. La Mirada..., op. cit., p. 225.

13 BRAVO, Isidre. La Mirada..., op. cit., p. 152-4.

14 AYENSA, José Ignacio. Estudiando..., op. cit., p. 28.

15 SCIELO. ¿Qué dice la Biblia sobre la homosexualidad? Disponible en: <http://www.scielo.cl/scielo.php?pid=s004934492001000400001\&script=sci_arttext>. Acceso en: 27 feb. 2021. 
homosexualidad, según algunos autores le atribuyen determinada restricción basadas en padrones históricos y culturales de la época. En este sentido:

Se trata del 'Código de Santidad' de los judíos, que contiene sus austeras normas rituales del culto a Yahveh. En este contexto, se explica bien la prohibición de las orgías sagradas de los cananeos, ligadas a los ritos idolátricos de la fertilidad en honor de Astarté y de Baal. Los cananeos creían participar en el proceso primaveral de los campos por la comunión vital con sus dioses de ambos sexos, a través de la unión carnal con prostitutas y prostitutos consagrados a ellos en sus templos. Por eso los hebreos, ante cuyos asombrados ojos se desarrollaban estas fiestas rituales de los pueblos vecinos, asociaban espontáneamente los actos homosexuales a la más depravada idolatría. Hay que tener en cuenta el marco histórico-cultural de la religión cananea de la fertilidad. ${ }^{16}$

Lo que implica decir que conforme se interpreta el contenido de los textos bíblicos, se le atribuye un verdadero rechazo a los temas de la cultura y de la idolatría humana, no necesariamente a la condenación de la práctica sexual homosexual, como a lo largo de los tiempos, ha sido realizada en la historia de las civilizaciones. Otro dato relevante que merece ser mencionado, cuanto la pena capital no estaba restricto a las prácticas homosexuales, pero también extendidos a los casos de adulterio, la bestialidad y el de acostarse con una mujer durante el período de menstruación - Levíticos 20, 10.15.18.

De un modo contrario a la condena de la homosexualidad, algunas instituciones religiosas vienen manifestándose a favor de la inclusión del colectivo homosexual en su comunidad, son los casos de la Asociación Unitaria Universalista ${ }^{17}$ en Norte América, la Iglesia Protestante Reformada y Inclusiva en Brasil $^{18}$, teniendo incluso determinados ritos específicos para el colectivo homosexual, como es el caso del rito del casamiento entre personas del mismo sexo, afirmando que la unión entre personas del mismo sexo deben ser entendida como una bendición de Dios. Así como ciertos ramos del Protestantismo, entre ellos: el unitarismo ${ }^{19}$, el anglicanismo tanto del Reino Unido, así como de los Estados Unidos de América.

Para algunas otras religiones, se acepta la homosexualidad, pero que incentivan el celibato, este posicionamiento puede encontrarse en el Kardecismo (atribuye al homosexual el factor del conflicto cárnico), en algunas religiones del Cristianismo, que procuran respetar, buscando la aceptación, como ocurre con la Iglesia Anglicana y algunos grupos de presbiterianos. ${ }^{20}$

Las ideologías del Budismo y del Hinduismo presentan influencia en el tema de la aceptación de la manifestación del deseo homosexual entre las personas. En ese caso, la primera incide en la relevancia de la orientación del deseo homosexual para la religión, pero sí una condición personal para esta religión, la vida sexual de sus participantes no es considerada determinante para la vida religiosa. De acuerdo con el segundo influyente ideal religioso en Asía, el Hinduismo, la homosexualidad es aceptada como perteneciente a la moral del individuo.

16 SCIELO. ¿Qué dice la Biblia sobre la homosexualidad? Disponible en: <http://www.scielo.cl/scielo.php?pid=s004934492001000400001\&script=sci_arttext>. Acceso en: 27 feb. 2021.

17 UUB. Unitário Universalismo Brasil. Disponible en: <http://unitariouniversalismo.wordpress.com/>. Acceso en: 27 feb. 2021.

18 BETEL. Notícias. Disponible en: <http://www.betelrj.com/modules/mastop_publish/?tac=Quem_somos>. Acceso en: 27 feb. 2021.

19 MIGUELSERVET.ORG. El Unitarismo: Fuentes Históricas y Realidad Actual. Disponible en: <http://www.miguelservet.org/ unitarismo.htm>. Acceso en: 27 feb. 2021.

20 VERBICARO SOARES, Douglas. Las mujeres y las personas homosexuales en las Fuerzas Armadas. Especial referencia a las FFAA brasileñas. Trabajo fin de curso Máster Oficial en Estudios Interdisciplinares de Género. Universidad de Salamanca. Salamanca, España, 2012, p. 76. 
Según la mitología hindú, existen relatos de relaciones entre criaturas del mismo sexo. Por otro lado esta aceptación de la religión podrá ser interpretada de manera diferente en países que sigan un ideario más radical, o que representaría la no aceptación de los homosexuales entre sus miembros. ${ }^{21}$

\section{La homosexualidad discutida según la visión del Papa Francisco}

Con la elección del Papa Francisco, las ideas de Iglesia Católica sobre la homosexualidad se mantienen en el sentido de reconocer la dignidad de los homosexuales mientras no practiquen actos de características homosexuales:

La particular inclinación de la persona homosexual, aunque en sí no sea pecado, constituye sin embargo una tendencia, más o menos fuerte, hacia un comportamiento intrínsecamente malo desde el punto de vista moral. Por este motivo la inclinación misma debe ser considerada objetivamente desordenada. ${ }^{22}$

Existen pensamientos de algunas personas más conservadoras en la religión católica que refuerzan la homosexualidad como pecado. Así:

La iglesia siempre ha enseñado que acto homosexual es un pecado grave. La congregación para la doctrina de la fe (CDF) ha declarado en 1975: en las Sagradas Escrituras estos actos son condenables como graves depravaciones y también presentados como tristes consecuencias de repudio por Dios (CDF, Declaración "Persona humana" sobre algunas cuestiones de ética sexual, número 8, 1975). ${ }^{23}$

La fuerte influencia religiosa también ha sido defendida, por ejemplo, en el caso Dudgeon, que será visibilizado en nuestra tesis, donde uno de los Jueces del caso, se pronunció al analizar la materia de los Derechos Humanos y relacionarla con los temas de las creencias religiosas y materiales (textos bíblicos) que influyen en el modo de pensar de las personas. El caso mencionado tiene como base el posicionamiento del Juez chipriota del Tribunal Europeo de Derechos Humanos, que se manifestó en la sentencia de la década de los 80 , que declaró que la legislación de Irlanda del Norte que condenaba la homosexualidad masculina era contraria a la previsión del Convenio Europeo de Derechos Humanos.

El lema que tiene que ver con nuestro estudio y merece ser mencionada es que el ideario religioso posé grande relación con la moral cultural de las personas y que ese punto de vista podrá hacer con que ciertos colectivos estén contrarios al reconocimiento de derechos a otros, como por ejemplo fue la justificación del Juez, que al ejemplificar en la doctrina católica y musulmana concuerdan en condenar la prácticas homosexuales y la sodomía. Para H. Català i Bas, en una visión muy acertada, preceptúa que: en gran medida las concepciones morales se fundamentan en creencias religiosas. ${ }^{24} \mathrm{Y}$ para que los problemas que puedan surgir en una determinada sociedad que los tienen en consideración se basaría en la educación para los valores democráticos, para la integración de la diversidad, entenderla como un instrumento preventivo.

Aduciremos el ejemplo de Kelsen que decía: la educación para la democracia es una de las principales exigencias de la democracia en sí misma. H. Català i Bas también, al citar Tomas

21 ABGLT: Manual de Comunicação LGBT. Lésbicas, Gays, Bissexuais, Travestis e Transexuais. Brasília, Brasil, 2010, p. 23.

22 ELÍAS, Cristina. Cultura Homosexual, Sujeto. Homosexual y Derechos Humanos. In: FORO. Revista de Ciencias Jurídicas y Sociales, Ensayos, No 5. Nueva Época. Madrid. España, 2007, p. 202.

23 VERBICARO SOARES, Douglas. Las mujeres..., op. cit., p. 76.

24 H. CATALÀ I BAS, Alexandre. Los derechos fundamentales como limite a costumbres y prácticas religiosas o culturales. In: V.AA.: Anuario de derecho parlamentario, $n^{\circ}$. 13, 2002, p. 173-4. 
y Valiente:

La educación humanista debe consistir en la enseñanza de la libertad. De ese modo podremos visibilizar en la Declaración del Comité de Ministros del Consejo de Europa sobre la intolerancia de 14 de mayo de 1981: persuadidos del papel fundamental de la educación y de la información en la acción contra la intolerancia, la cual tiene frecuentemente su origen en la ignorancia, fuente de incomprensión, de odio, e incluso de violencia. ${ }^{25}$

Del mismo modo en que la Conferencia Mundial de Derechos Humanos preceptúa que la educación es el instrumento necesario, así como la capacitación y la información social en materia de los Derechos Humanos, justo para la promoción y el establecimiento de la armonía social, la formación de bases estables entre las comunidades y trabajar a favor de la comprensión mutua entre las personas.

Como bien resalta Triani: el papel de una educación dinámica para la formación y la conciencia, usándose de los valores analíticos, críticos, comparativos de las realidades enfrentadas y en la presentación de soluciones, buscando en ellas una mayor capacitación y la visualización de ese proceso educativo relacionado con un buen sentido común. ${ }^{26}$ De ese modo en un raciocinio análogo, podemos utilizar de sus ideas en la fundamentación de que la educación como mecanismo de cambio necesario para dar efectividad a los Derechos Humanos y la consecución del bien común, como supra añadido.

De momento, nos centraremos en los asuntos de la influencia religiosa católica cristiana en la condena de la homosexualidad. Si adentramos en la página oficial del Vaticano, encontraremos distintos textos que se manifiestan sobre la homosexualidad, entre ellos, merece destaque uno que preceptúa ese temario a la anomalía social, como por ejemplo se puede identificar:

Una problemática particular, que se puede manifestar durante el proceso de maduración-identificación sexual, es lo de la homosexualidad, que, se difunde cada vez más en las culturas urbanas. Es necesario que este fenómeno sea presentado con equilibrio de razón, a la luz de los documentos de la Iglesia. Los jóvenes precisan de ser ayudados a distinguir los conceptos de normalidad y de anomalía, de la culpa sugestiva y de desorden objetiva, evitando inducir hostilidad y, por otro lado, esclareciendo bien la orientación estructural y complementar de la sexualidad en relación a la realidad del matrimonio, de la procreación y de la castidad cristiana. La homosexualidad designa las relaciones entre hombres o mujeres que experimentan una atracción sexual exclusiva u predominante para con personas del mismo sexo. Reviste formas muy variadas, a través de los siglos y de las diferentes culturas. A su génesis psíquica continua en grande parte por explicar. Es preciso distinguir la tendencia, que puede ser innata, y los actos de homosexualidad que son intrínsecamente desordenados y contrarios a la ley natural. ${ }^{27}$

Así como también es vislumbrado en la siguiente explanación:

En muchos de los casos, especialmente cuanto la práctica de actos homosexuales no se han estructurado, pueden ser ayudados positivamente por medio de una terapia apropiada. De cualquier manera, las personas que están en esta condición deben ser acogidas con respeto, dignidad y delicadeza, evitando todas las formas

25 Cf. H. CATALÀ I BAS, Alexandre. Los derechos fundamentales..., loc. cit., p. 207-8.

26 TRIANI, Pierpaolo. Il dinamismo della coscienza e la formazione. Pubblicazioni dell Università Católica del Sacro Cuore. Milano, Itália, 1998, p. 327.

27 VATICAN. Sexualidad Humana: verdade e significado. Disponible en: <http://www.vatican.va/roman_curia/pontifical_ councils/family/documents/rc_pc_family_doc_08121995_human-sexuality_po.html>. Acceso en: 27 feb. 2021. 
de injusta discriminación. Los padres, por su lado, en el caso de constataren a sus hijos, en edad infantil $\mathrm{u}$ adolescente, el aparecimiento de tal tendencia $\mathrm{u}$ de los comportamientos con ella relacionados, háganse ayudar por personas especializadas e cualificadas para dar todo el tipo de auxilio posible. ${ }^{28}$

O igualmente previsto en continuación:

Para la mayor parte de las personas homosexuales, esa condición supone una prueba. Por eso deben ser acogidas en respeto, compasión y delicadeza. Estas personas son llamadas a realizar, en sus vidas, la voluntad de Dios y, se son cristianas, a unir al sacrificio de la cruz del Señor a las dificultades que pueden encontrar debido a su condición. Las personas homosexuales son llamadas a la castidad. ${ }^{29}$

Del mismo modo que las consideraciones previas mencionadas, se hacen pertinentes las declaraciones del Papa Francisco, en el año de 2013, cuando se manifiesta sobre la dignidad de las personas homosexual y el reconocimiento de la misma. Dos momentos merecen nuestra apreciación, el primero durante las Jornadas de la Juventud de julio del mismo año en Brasil, donde la periodista ítalo-brasileńa Ilze Scamparini le ha indagado al Santo Pontífice sobre el tema del lobby gay.

Según las palabras de la periodista:

Quisiera pedirle permiso para hacer una pregunta un poco delicada: hay otra imagen que también ha dado la vuelta al mundo, que ha sido la de Monseñor Ricca y las noticias sobre su intimidad. Quisiera saber, Santidad, ¿qué pretende hacer en esta cuestión? ¿Cómo afrontar esta cuestión y cómo Su Santidad pretende afrontar toda la cuestión del lobby gay?

De este modo aclarar la propia opinión de Pontífice de la Iglesia Católica Apostólica Romana cuanto a los episodios relacionados con supuestos casos de personas homosexuales relacionadas con la Cúpula de la Iglesia.

En esta ocasión en Papa Francisco se pronunció del siguiente modo lo del Monseñor Ricca $^{30}$ :

He hecho lo que el Derecho Canónico manda hacer, que es la investigación previa. Y en esta investigado no hay nada de lo que le acusan, no hemos encontrado nada de eso. Ésa es la respuesta. Pero quisiera añadir otra cosa sobre esto: Yo veo que muchas veces en la Iglesia, independientemente de este caso, pero también en este caso, se van a buscar "pecados de juventud", por ejemplo, y se publican. No los delitos, ¡eh!, los delitos son otra cosa: el abuso de menores es un delito. No, los pecados. Pero si una persona, laica o sacerdote o religiosa, ha cometido un pecado y después se convierte, el Señor perdona, y cuando el Señor perdona, el

28 VATICAN. Sexualidad Humana: verdade e significado. Disponible en: <http://www.vatican.va/roman_curia/pontifical_ councils/family/documents/rc_pc_family_doc_08121995_human-sexuality_po.html>. Acceso en: 27 feb. 2021.

29 En la misma argumentación se presenta la terapia apropiada para tratar de la homosexualidad: en mucho de los casos, especialmente cuando las prácticas homosexuales todavía no se han materializado las terapias pueden ser utilizadas para ayudar a los pacientes. Aunque las personas que están en esta condición deberán ser acogidas con respeto, dignidad y delicadeza, evitando todas las formas de discriminación hacia a ellas [...] las personas homosexuales son llamadas a la castidad y ese sacrificio para superar la dificultad enfrentada para satisfacer la voluntad de Dios. VATICAN. Sexualidad Humana: verdade e significado. Disponible en: <http://www.vatican.va/roman_curia/pontifical_councils/family/documents/ rc_pc_family_doc_08121995_human-sexuality_po.html>. Acceso en: 27 feb. 2021.

30 PROCESO. Romance gay entre asesor del Papa y militar suizo sacude el vaticano. Disponible en: <http://www.proceso.com. $\mathrm{mx} /$ ?p=348185>. Acceso en: 27 feb. 2021. 
Señor olvida y esto para nuestra vida es importante. Cuando vamos a confesarnos y decimos de verdad: "He pecado en esto", el Señor olvida y nosotros no tenemos derecho a no olvidar, porque corremos el riesgo de que el Señor no se olvide de nuestros pecados. Es un peligro éste. Esto es importante: una teología del pecado. Muchas veces pienso en san Pedro: cometió uno de los peores pecados, renegar de Cristo, y con este pecado lo hicieron Papa. Tenemos que pensarlo bien. Pero, volviendo a su pregunta más concreta, en este caso, he realizado la investigación previa y no hemos encontrado.

Ésta había sido la primera pregunta de la entrevistadora. La intervención posterior ha sido relacionada con el supuesto lobby gay que ha ganado proyección en los medios de comunicación.

En contestación, el Papa Francisco respondió:

Además, usted hablaba del lobby gay. Bien, se escribe mucho del lobby gay. Todavía no he encontrado quién me enseñe un carnet de identidad que diga "gay" en el Vaticano. Dicen que los hay. Creo que cuando uno se encuentra con una persona así, debe distinguir el hecho de ser una persona gay, del hecho de hacer un lobby, porque ningún lobby es bueno. Son malos. Si una persona es gay y busca al Señor y tiene buena voluntad, ¿quién soy yo para juzgarla? El Catecismo de la Iglesia Católica explica esto de una manera muy hermosa; dice... Un momento, cómo se dice... y dice: "No se debe marginar a estas personas por eso, deben ser integradas en la sociedad". El problema no es tener esta tendencia; no, debemos ser hermanos, porque éste es uno, pero si hay otro, otro. El problema es hacer el lobby de esta tendencia: lobby de avaros, lobby de políticos, lobby de los masones, tantos lobby. Éste es el problema más grave para mí. ${ }^{31}$

De acuerdo con algunas declaraciones del Papa Francisco:

Una persona homosexual tiene buena voluntad y busca a Dios, yo no soy quién para juzgarla ${ }^{32}$ así como: en esta vida Dios acompaña a las personas y es nuestro deber acompañarlas a partir de su condición. Hay que acompañar con misericordia. Cuando sucede así, el Espíritu Santo inspira al sacerdote la palabra oportuna. ${ }^{33}$

Del mismo modo, sus palabras no son aceptadas por un consenso en el Vaticano, es decir, otros miembros de la Iglesia Católica tienen posicionamientos diferentes, como ha sido el del año siguiente, dónde en unas declaraciones se ha manifestado: El Cardenal español nombrado por el Papa Francisco.

Para Sebastián, él no cree que vaya a cambiar la visión de la iglesia sobre este tema, según sus ideas:

Muchos se quejan y no lo toleran, pero con todos los respetos digo que la homosexualidad es una manera deficiente de manifestar la sexualidad, porque ésta tiene una estructura y un fin, que es el de la procreación. Una homosexualidad que no puede alcanzar ese fin está fallando. Eso no es un ultraje para nadie. En nuestro cuerpo tenemos muchas deficiencias. Yo tengo hipertensión, ¿̇me voy a enfadar porque me lo digan? Es una deficiencia que tengo que corregir como pueda. El señalar a un homosexual una deficiencia no es una ofensa, es una ayuda

31 VATICAN. Conferencia de prensa del Santo Padre Francisco durante el vuelo de regreso a Roma. Disponible en: <http://www. vatican.va/holy_father/francesco/speeches/2013/july/documents/papa-francesco_20130728_gmg-conferenza-stampa_ sp.html>. Acceso en: 27 feb. 2021

32 OCIOGAY. Francisco critica que la iglesia esté obsesionada con el matrimonio homosexual. Disponible en: <http://www. ociogay.com/2013/09/20/francisco-critica-que-la-iglesia-este-obsesionada-con-el-matrimonio-homosexual/>. Acceso en: 27 feb. 2021.

33 VATICAN. Entrevista al Papa Francisco. Disponible en: <http://www.vatican.va/holy_father/francesco/speeches/2013/ september/documents/papa-francesco_20130921_intervista-spadaro_sp.html>. Acceso en: 27 feb. 2021. 
porque muchos casos de homosexualidad se pueden recuperar y normalizar con un tratamiento adecuado. No es ofensa, es estima. Cuando una persona tiene un defecto, el buen amigo es el que se lo dice. ${ }^{34}$

Corroboramos esa idea con el contenido disponible por el Vaticano referente a la Congregación para la educación católica, referente a las personas homosexuales, antes de entraren en el seminario y a las órdenes institucionales de la Iglesia Católica. Según las directrices del modelo:

En continuidad con la enseñanza del Concilio Vaticano II y, en particular, con el decreto Optatam totius sobre la formación sacerdotal, la Congregación para la Educación Católica ha publicado diversos documentos con el fin de promover la adecuada formación integral de los futuros sacerdotes, ofreciendo orientaciones y normas precisas acerca de varios de sus aspectos. El Sínodo de los Obispos de 1990 también reflexionó sobre la formación de los sacerdotes en las circunstancias actuales, con la intención de aplicar la doctrina conciliar sobre este tema y hacerla más explícita y adecuada al mundo contemporáneo. Como fruto de este Sínodo, Juan Pablo II publicó la Exhortación Apostólica Postsinodal Pastores dabo vobis. ${ }^{35}$

Según el Sínodo, celebrado en el mes de Octubre de 2014, al final, las discusiones sobre la aceptación de los homosexuales a la atención pastoral no han sido aprobadas por un mínimo exigido de dos tercios y se quedo fuera del texto final del Sínodo mencionado, pero debemos reconocer que ha sido una de las primeras veces que el Vaticano ha tratado el tema de modo más abierto para el mundo.

En el texto previo el que consideraba la aceptación de homosexuales en la Orden Religiosa, es decir, dentro del seminario o en las órdenes sagradas, con según el propio texto con tendencias homosexuales profundamente arraigadas. Según material del Vaticano: citado como la homosexualidad y el misterio ordenado, se hace referencia desde el Concilio Vaticano II, añadiéndole distintos instrumentos del Catecismo, que tratan de la temática homosexual, haciendo una distinción entre los actos homosexuales y las tendencias homosexuales.

Como claramente preceptúa el primero es considerado como un pecado grave, como actos inmorales y contrarios a la ley natural. De este modo su celebración será considerada como pecaminosa e inaceptable. Ya las tendencias, serían algún tipo de desorden y que sirven de pruebas para las personas que sufren de esas tendencias homosexuales profundas. Para esos casos, las personas deberán ser acogidas con delicadeza, respeto para que no incidan sobre las mismas un cierto estigma que genere una discriminación. Para el documento presentado, que hace referencia de que esas personas, que sufren de estos casos, que están llamadas a realizar la voluntad de Dios en sus vidas y a unir al sacrificio de la cruz las dificultades que puedan encontrar. ${ }^{36}$

El texto estudiado termina con la siguiente argumentación:

A la luz de tales enseñanzas este, de acuerdo con la Congregación para el culto divino y la disciplina de los sacramentos, cree necesario afirmar con claridad que la iglesia, respetando profundamente a las personas en cuestión, no puede admitir

34 PÚBLICO.ES. El cardenal español nombrado por Francisco: "La homosexualidad se puede normalizar con tratamiento". Disponible en: <http://www.publico.es/actualidad/496414/el-nuevo-cardenal-espanol-la-homosexualidad-es-deficiente-yse-puede-normalizar-con-tratamiento>. Acceso en: 27 feb. 2021.

35 VATICAN. Congregación para la educación católica: instrucción. Disponible en: <http://www.vatican.va/roman_curia/ congregations/ccatheduc/documents/rc_con_ccatheduc_doc_20051104_istruzione_sp.html>. Acceso en: 27 feb. 2021.

36 VATICAN. Congregación para la educación católica: instrucción. Disponible en: <http://www.vatican.va/roman_curia/ congregations/ccatheduc/documents/rc_con_ccatheduc_doc_20051104_istruzione_sp.html>. Acceso en: 27 feb. 2021. 
al Seminario y a las órdenes Sagradas a quienes practican la homosexualidad, presentan tendencias homosexuales profundamente arraigadas o sostienen la así llamada cultura gay. ${ }^{37}$

En los argumentos defendidos por la Iglesia también estarían:

Las personas homosexuales se encuentran en una situación que obstaculiza gravemente una correcta relación con hombres y mujeres. De ningún modo pueden ignorarse las consecuencias negativas que se pueden derivar de la Ordenación de personas con tendencias homosexuales profundamente arraigadas. Si se tratase, en cambio, de tendencias que fuesen sólo la expresión de un problema transitorio, como, por ejemplo, el de una adolescencia todavía no terminada, ésas deberían ser claramente superadas al menos tres años antes de la Ordenación diaconal. ${ }^{38}$

En este sentido, al final, las personas que tienen un orientación homosexual acaban siendo impedidas que ingresar en la Institución religiosa.

\section{Consideraciones finales}

Ante la previsión de prácticas discriminatoria hacia las personas homosexuales, en destaque en relación al ideal de la ideología cristiano católica. La investigación concluyó que validos son los estudios que explicitan discusiones sociales sobre diversas cuestiones relacionadas a las personas en situación de vulnerabilidad en el país.

El estudio sobre la realidad brasileña en la comprensión de la diversidad sexual y su relación con la ideología religiosa son relevantes para un cambio de paradigmas y la construcción de una sociedad global basadas en el respeto y la no discriminación, no solamente en el ambiente de las Iglesias Cristianas, pero en un contexto más amplio.

En destaque la presente investigación resalta que son necesarios novedosos trabajos/ proyectos de sensibilización que motiven las distintas sociedades por el mundo en la aceptación de la diversidad sexual y, también, en el desarrollo de los estudios en Derechos Humanos. El papel de las ideologías religiosas es indispensable en la estructura basilar de los seres humanos, justamente en el ideal de fe y dignidad. Por lo tanto, la justificativa de no aceptación o condena, motivadas por orientación sexual pierde espacio frente a los desafíos de búsqueda por la esencia humana y la expresión de sus humanidades.

\section{Referencias}

ABGLT. Manual de Comunicaçáo LGBT. Lésbicas, Gays, Bissexuais, Travestis e Transexuais. Brasilia, Brasil, 2010.

ACIPRENSA. La enseńanza de la Iglesia Católica sobre la homosexualidad. Disponible en: <http://www.aciprensa.com/Familia/homosex-catolicis.htm>. Acceso en: 26 feb. 2021.

AYENSA, José Ignacio. Estudiando La Homosexualidad. Teoría e investigación. 1a Edición,

37 VATICAN. Congregación para la educación católica: instrucción. Disponible en: <http://www.vatican.va/roman_curia/ congregations/ccatheduc/documents/rc_con_ccatheduc_doc_20051104_istruzione_sp.html>. Acceso en: 27 feb. 2021.

38 VATICAN. Congregación para la educación católica: instrucción. Disponible en: <http://www.vatican.va/roman_curia/ congregations/ccatheduc/documents/rc_con_ccatheduc_doc_20051104_istruzione_sp.html>. Acceso en: 27 feb. 2021. 
Ediciones Pirámide. Madrid, España, Ediciones Pirámide, 2008.

BETEL. Notícias. Disponible en: <http://www.betelrj.com/modules/mastop_ publish/?tac=Quem_somos>. Acceso en: 27 feb. 2021.

BRAVO, Isidre. La Mirada de Zeus. Antología sobre la fascinación masculina por los muchachos en la literatura griega y latina. $1^{\text {a }}$ Edición. Ediciones de la Tempestad. Barcelona, España, 2007.

ELÍAS, Cristina. Cultura Homosexual, Sujeto. Homosexual y Derechos Humanos. In: FORO. Revista de Ciencias Jurídicas y Sociales, Ensayos, No 5. Nueva Época. Madrid. España, 2007.

FELGT. La Iglesia Católica y la homosexualidad. Disponible en: <http:/www.felgt.org/files/ docs/d9474064b9f6.pdf>. Acesso en: 26 feb. 2021.

FERREIRA FILHO, Manoel. Direitos humanos fundamentais. Editora Saraiva. 4a Edição. São Paulo, Brasil, 2000.

H. CATALÀ I BAS, Alexandre. Los derechos fundamentales como limite a costumbres y prácticas religiosas o culturales. In: V.AA.: Anuario de derecho parlamentario, no. 13, 2002.

IZQUIERDO, Alejandro. Evolución del Derecho de Igualdad de Lesbianas y Gais. Trabajo de Grado. Universidad de Salamanca: Programa de Doctorado Pasado y presente de los derechos humanos, Salamanca, España, 2006.

LAMAREA. Llega a España el Manual del Vaticano contra la homosexualidad. Disponible en: <http://www.lamarea.com/2013/06/11/la-iglesia-publica-en-castellano-un-manual-paratratar-la-homosexualidad/>. Acceso en: 26 feb. 2021.

MIGUELSERVET.ORG. El Unitarismo: Fuentes Históricas y Realidad Actual. Disponible en: <http://www.miguelservet.org/unitarismo.htm>. Acceso en: 27 feb. 2021.

OCIOGAY. Francisco critica que la iglesia esté obsesionada con el matrimonio homosexual. Disponible en: <http://www.ociogay.com/2013/09/20/francisco-critica-que-laiglesia-este-obsesionada-con-el-matrimonio-homosexual/>. Acceso en: 27 feb. 2021.

PROCESO. Romance gay entre asesor del Papa y militar suizo sacude el vaticano. Disponible en: <http://www.proceso.com.mx/?p=348185>. Acceso en: 27 feb. 2021.

PÚBLICO.ES. El cardenal espańol nombrado por Francisco: "La homosexualidad se puede normalizar con tratamiento". Disponible en: <http://www.publico.es/ actualidad/496414/el-nuevo-cardenal-espanol-la-homosexualidad-es-deficiente-y-se-puedenormalizar-con-tratamiento>. Acceso en: 27 feb. 2021.

SCIELO. ¿Qué dice la Biblia sobre la homosexualidad? Disponible en: <http://www.scielo.cl/ scielo.php?pid=s0049-34492001000400001\&script=sci_arttext>. Acceso en: 27 feb. 2021.

TRIANI, Pierpaolo. Il dinamismo della coscienza e la formazione. Pubblicazioni dell’Università Católica del Sacro Cuore. Milano, Itália, 1998.

UUB. Unitário Universalismo Brasil. Disponible en: <http://unitariouniversalismo. wordpress.com/>. Acceso en: 27 feb. 2021. 
VATICAN. Conferencia de prensa del Santo Padre Francisco durante el vuelo de regreso a Roma. Disponible en: <http:/www.vatican.va/holy_father/francesco/speeches/2013/july/ documents/papa-francesco_20130728_gmg-conferenza-stampa_sp.html>. Acceso en: 27 feb. 2021.

VATICAN. Congregación para la educación católica: instrucción. Disponible en: <http:// www.vatican.va/roman_curia/congregations/ccatheduc/documents/rc_con_ccatheduc_ doc_20051104_istruzione_sp.html>. Acceso en: 27 feb. 2021.

VATICAN. Entrevista al Papa Francisco. Disponible en: <http://www.vatican.va/holy_ father/francesco/speeches/2013/september/documents/papa-francesco_20130921_intervistaspadaro_sp.html>. Acceso en: 27 feb. 2021.

VATICAN. Sexualidad Humana: verdade e significado. Disponible en: < http://www.vatican. va/roman_curia/pontifical_councils/family/documents/rc_pc_family_doc_08121995_humansexuality_po.html>. Acceso en: 27 feb. 2021.

VERBICARO SOARES, Douglas. Las mujeres y las personas homosexuales en las Fuerzas Armadas. Especial referencia a las FFAA brasileñas. Trabajo fin de curso Máster Oficial en Estudios Interdisciplinares de Género. Universidad de Salamanca. Salamanca, España, 2012. 